This item was submitted to Loughborough's Research Repository by the author.

Items in Figshare are protected by copyright, with all rights reserved, unless otherwise indicated.

\title{
A comparison of CFD and full-scale measurements for analysis of natural
} ventilation

PLEASE CITE THE PUBLISHED VERSION

PUBLISHER

(c) VEETECH Ltd

VERSION

AM (Accepted Manuscript)

LICENCE

CC BY-NC-ND 4.0

\section{REPOSITORY RECORD}

Yang, Tong, N.G. Wright, D.W. Etheridge, and A.D. Quinn. 2019. "A Comparison of CFD and Full-scale Measurements for Analysis of Natural Ventilation". figshare. https://hdl.handle.net/2134/5257. 
This item was submitted to Loughborough's Institutional Repository (https://dspace.lboro.ac.uk/) by the author and is made available under the following Creative Commons Licence conditions.

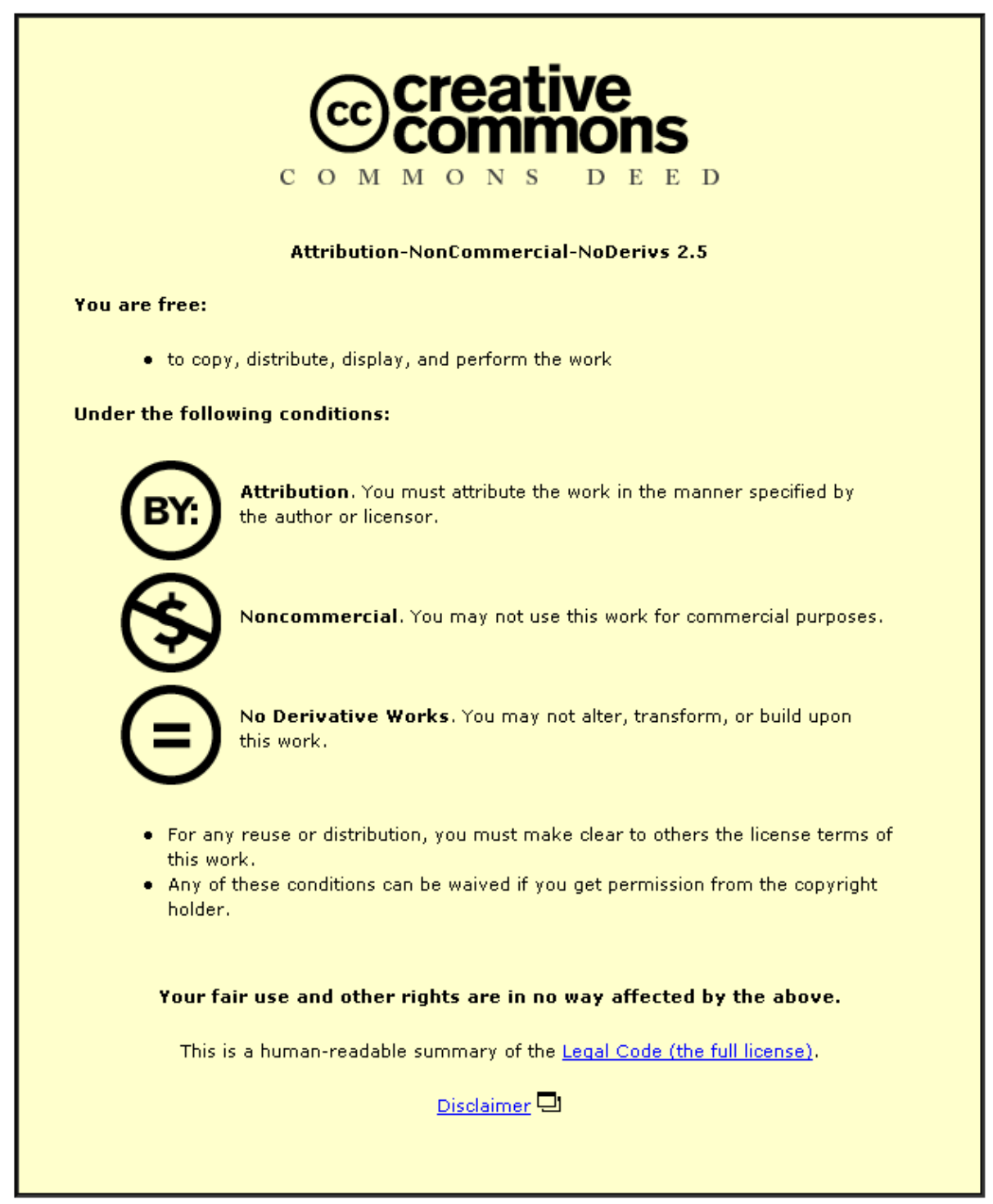

For the full text of this licence, please go to: http://creativecommons.org/licenses/by-nc-nd/2.5/ 


\title{
A Comparison of CFD and Full-scale Measurement for Analysis of Natural Ventilation
}

\author{
T Yang $^{1}$, NG Wright ${ }^{1}$, DW Etheridge ${ }^{2}$ and AD Quinn ${ }^{3}$ \\ ${ }^{1}$ School of Civil Engineering, University of Nottingham, University Park, Nottingham, \\ NG7 2RD, UK \\ ${ }^{2}$ School of the Built Environment, University of Nottingham, University Park, \\ Nottingham, NG7 2RD, UK \\ ${ }^{3}$ School of Engineering, University of Birmingham, Edgbaston, Birmingham \\ B15 2TT, UK
}

\begin{abstract}
CFD modelling techniques have been used to simulate the coupled external and internal flow in a cubic building with two dominant openings. CFD predictions of the time-averaged cross ventilation flow rates have been validated against full-scale experimental data under various weather conditions in England. RANS model predictions proved reliable when wind directions were near normal to the vent openings. However, when the fluctuating ventilation rate exceeded the mean flow, RANS models were incapable of predicting the total ventilation rate. Improved results are expected by applying more sophisticated turbulence models, such as LES or weighted quasi-steady approximations.
\end{abstract}

Key words: Natural ventilation, CFD, envelope flow theory, wind, buoyancy, full-scale experiment, comparisons

\section{Introduction}

The successful application of natural ventilation techniques provides good indoor air quality and thermal comfort for the occupants whilst also reducing sick building syndrome (SBS). As well as improving the productivity of occupants, it can also save energy and reduce $\mathrm{CO}_{2}$ emissions. In such systems the natural variations in wind and thermal buoyancy forces continuously change the ventilation flow into a building which must be reflected in engineering practice whilst balancing demands for the rapid turnaround of optimum design solutions. When evaluating ventilation performance, Computational Fluid Dynamics (CFD) simulations can have advantages over other theoretical models and experimental measurements, especially for sophisticated buildings within a complex built environment. CFD can provide detailed information about indoor flow patterns, temperature, air movement, indoor pollutants and local draught distribution, etc.
CFD techniques in natural ventilation studies have often been applied by modelling external flow around buildings and indoor thermal comfort simulation separately $[1,2]$. However, this separation may lead to errors as ventilation openings will alter the external flow pattern and imposing correct boundary conditions for detailed indoor flow simulations can be a difficult engineering judgement in design practice, especially with complex surrounding obstructions. Advances in CFD and increased computer power now mean that with careful application the simulation of combined indoor and outdoor airflows is becoming feasible.

Recent simulations of flow through large openings include those in wind tunnel models [3]; in a fullscale building placed in a wind tunnel [4] and in a full-scale building located in an open country site [5]. The differences between wind tunnel data and field measurements have been highlighted in the comparison study of flows around a cubic building [6]. Wind tunnel scaling effects introduced by combined wind and buoyancy forces may have significant effects on ventilation through both large 
and small openings. There is little parallel CFD, wind tunnel and full-scale testing data available.

The key objective of the work presented here was to evaluate the effectiveness with which CFD can capture the coupled external and internal flow fields under natural wind and buoyancy forces. Relatively few experimental studies have been undertaken for cross ventilation in a full-scale cube with small openings in natural environment. The field data collected and reported here contribute to the small database of information on generic building forms and is valuable for CFD model validations. Comparisons of CFD simulations, envelope flow theories and experimental measurements for the assessment of mean ventilation rates of a $6 \mathrm{~m}$ cube are presented.

The numerical methodology of the CFD code is explained with regard to issues related to the computational domain, boundary conditions and grid sensitivity studies in Section 2, followed by a brief description of theoretical envelope flow models in Section 3. Next, in Section 4, the experimental methodology and procedures are summarised. Section 5 presents CFD simulation results against full-scale experimental data in terms of the mean ventilation rates. Finally, discussion and conclusions are given in Sections 6 and 7.

A cubic building represents a generic bluff body. The study of turbulent flow around it can enhance the understanding of the complex flow physics and also eliminates the influence of the geometric parameters (i.e. building shape, aspect ratio and roof pitch) on the flow pattern and corresponding pressure distributions [7, 8]. Naturally ventilated buildings are normally categorized as either isolated or connected spaces. An isolated cube with two simple purpose-provided ventilation openings can well represent the simplest form for design practice. Therefore, in order to carry out the field studies for cross ventilation in buildings and bypass the weakness of inaccurate CFD predictions of the flow reattachment on the roof $[9$, $10,11]$ by placing the openings on the side walls not the roof, the test building was chosen as a full-scale $6 \mathrm{~m}$ cube with two rectangular openings in opposite walls (see Figure 1). Further to the wind tunnel studies of Carey and Etheridge [12], the two openings are designed to be identical, each with a size of 0.35 $\mathrm{m} \times 0.25 \mathrm{~m}$; therefore the ratio of the opening area to wall area is $0.24 \%$. The openings are located along the cube centreline, $1 \mathrm{~m}$ above the ground and $1 \mathrm{~m}$ below the roof respectively. The wind direction is defined in Figure 2, the $0^{\circ}$ indicates the direction of the wind blowing perpendicularly to the cube surface through the lower level ventilation opening.

\section{CFD simulation}

CFD solutions are obtained with CFX5 (version 5.5.1), which is a general-purpose, unstructured-grid CFD code [13]. CFX5 uses a finite element based finite volume method to model the equations for the conservation of mass, momentum and energy in terms of the dependent variables and pressure in their Reynolds time-averaged form. Turbulent effects are taken account by Reynolds-averaged Navier-Stokes (RANS) turbulence models. The solution variables are discretised on a co-located grid with a second order fully conservative vertex based scheme. The resulting equation system is solved with a fully coupled Algebraic Multi-Grid (AMG) solver [14].

In the present study the standard k- $\varepsilon$ and RNG k- $\varepsilon$ turbulence models are applied. Recently Cheng et al. [15] compared the performance of LES with the standard k- $\varepsilon$ model for a fully developed turbulent flow over a matrix of cubes. Based on the detailed comparisons between the CFD predictions and the corresponding wind tunnel experimental data, the authors concluded that both LES and standard k- $\varepsilon$ model were able to predict the main characteristics of the mean flow in the array of cubes reasonably well.

Both standard k- $\varepsilon$ and RNG k- $\varepsilon$ models in CFX5 are used in combination with a scalable wall function [13]. With a built-in lower limit for $y+$ (the nondimensional wall distance), the scalable near wall treatment ensures that the wall function is applied only in the log-law region, which allows for consistent grid refinement near the wall. Sensitivity studies (detailed in $[16,17]$ ) have been carried out in line with best practice guidelines for CFD applications $[18,19]$.

\subsection{Computational domain and mesh}

The computational domain size was set as $5 H$ ( $H=$ building height) upstream and $10 H$ downstream, $5 H$ away from each side of the cube and $5 H$ above the cube. In order to prevent any distortions of the 
inlet velocity profile and the full development of turbulent flow, domain dimensions should cover sufficient regions around the building [20]. The domain size independency has been tested satisfactorily in previous studies by Easom [21].

An unstructured mesh consisting of approximately 1 million tetrahedral and prismatic cells was used for the simulations. Cells were uniformly distributed within the building space, and refined at ventilation openings, on cube surfaces and building edges. An illustration of the unstructured mesh is shown in Figure 3. Grid sensitivity tests are explained in Section 2.3.

\subsection{Boundary conditions}

The boundary conditions for steady state solutions of the wind effect cases are listed in Table 1.

Based on the results of Richards and Hoxey [22] the incoming wind profile is expressed as:

$$
\begin{aligned}
& U(z)=\frac{u_{*}}{\kappa} \ln \left(z / z_{0}\right) \\
& u_{*}=\frac{\kappa U_{r e f}}{\ln \left(z_{r e f} / z_{0}\right)} \\
& k=\frac{u_{*}^{2}}{\sqrt{C_{\mu}}} \\
& \varepsilon=\frac{u_{*}^{3}}{\kappa\left(z+z_{0}\right)}
\end{aligned}
$$

where

$z_{\text {ref }}=$ reference height $(6 \mathrm{~m})$

$U_{r e f}=$ reference wind speed at reference height

$z_{0} \quad=$ ground roughness height

$C_{\mu}=0.09$ (the model constant)

$K=0.41$ (the von Karman constant)

\subsection{Grid dependency tests}

In order to assess the accuracy of different mesh sizes and capture detailed flow features through the openings, three types of meshes were used and named according to the resolution on the cube surface (the ratio of the cube height to the length scale of the mesh element). These settings are listed in Table 2.

The convergence criterion used on the three grids was the root-mean-square (RMS) of normalised residual for all variables to be less than $1 \times 10^{-4}$. Using the standard $k-\varepsilon$ turbulence model, the pressure coefficient $\left(C_{p}\right)$ distributions along the vertical centreline of the cube differed negligibly for these grids, except for a maximum difference of 0.07 which occurred on the leeward wall halfway toward the ground. At the two tapping points $0.5 \mathrm{~m}$ away from the centre of each opening along the vertical centreline (see Figure 1), on the fine grid (Grid40) the $C_{p}$ value had a $3 \%$ (or 5\%) difference from the other two grids.

All three grids (Grid15, Grid20 \& Grid40) were used to obtain solutions using the 2 nd order discretisation scheme with a convergence criterion of two more orders of magnitude than the original solution, i.e. from the order of $10^{-4}$ (RMS) to $10^{-6}(\mathrm{RMS})$. Comparison of the resulting quantities, such as the area-weighted mean speed and the mass flow rate through ventilation opening, showed that the convergence differences affected these three solutions at the level of less than 5\% (mean speed) or 1\% (mass flow rate). Therefore, in the case of obtaining the mean flow rate through opening by integration of velocity components, the solution on Grid40 at convergence level $10^{-6}$ (RMS) is required. In other cases concerning only the pressure distribution around the opening, the result on Grid15 at level $10^{-4}$ (RMS) is adequate.

Solutions with the RNG $k-\varepsilon$ turbulence model have also been investigated. Converged results with the $2^{\text {nd }}$ order discretisation scheme were achieved at the order of $10^{-4}$ (RMS). The RNG $k-\varepsilon$ model results on the three grids have also compared to the reference case by the standard the $k-\varepsilon$ model (i.e. results on Grid40 at $10^{-6}$ level). On Grid 20 and Grid40, there was an increase of approximately $5 \%$ in the mean speed predicted through the lower opening compared with reference case. Similarly there was an increase of $13 \%$ for the higher opening. A smaller than 5\% increase of the mean speed was predicted on Grid15. When the complexity of the turbulence model increases, numerical stability reduces. For the RNG $k-\varepsilon$ model results, the mass flow rate through the 
lower opening was different from the upper opening by $7 \%, 11 \%$ and $8 \%$ on Grid 15 , Grid 20 and Grid 40 respectively. This is due to interpolation inaccuracies introduced by the grid resolution at these positions. Convergence to lower residuals with this method was not possible. This is possibly due to the unsteady physical effects that are incorrectly omitted in a steady state model. In these cases, the only stable solution is an unsteady one (Prevezer 2002).

Both turbulence models produced a similar pressure distribution on the windward wall. On average, applying the RNG $\mathrm{k}-\varepsilon$ model consumed about 1 day more CPU time than the standard $\mathrm{k}-\varepsilon$ model to achieve the convergence level of $10^{-4}$ (RMS) on the three types of grids. The differences of flow field variables from the grid and turbulence model sensitivity tests were all below $10 \% \sim 15 \%$. As it is common to accept a tolerance of $\pm 10 \% \sim 15 \%$ uncertainty in full-scale and wind tunnel measurements, a compromise between accuracy and computational cost was made to investigate more scenarios under various wind directions on the fine grid at the convergence level of $1 \times 10^{-4}$ (RMS) with the standard $k-\varepsilon$ model.

\section{Envelope flow theories}

\subsection{Theoretical envelope flow models}

Envelope flow models for ventilation studies are normally categorized by the assumptions made for the flow and continuity equations. A brief description of steady and unsteady envelope flow models are summarised by Etheridge [23]. Amongst these models the simplest steady model, i.e. the pseudo-steady model, is commonly adopted for design procedures.

\subsection{Pseudo-steady model}

The pseudo-steady model requires knowledge of the time-averaged pressure differences across the opening, corresponding to pressures at specified points on the inlet and outlet sides. In this model it is assumed that the time-averaged flow quantities follow the same relationship as for truly steady flow. The Boussinesq approximation is used which states that the difference between the internal and external densities can be neglected in the continuity equation.
As indicated in Figure 4, for a single zone building with two equal dominant openings, the ventilation flow rate induced by combined wind and buoyancy effects is described as:

$$
\begin{aligned}
& Q=C_{d} A \sqrt{\left|\frac{\Delta P}{\rho}+\frac{\Delta T g h}{T_{e}}\right|} \\
& \text { or } \\
& Q=C_{d} A \sqrt{\frac{\left|\frac{\Delta P}{\rho}-\frac{\Delta T g h}{T_{e}}\right|}{\rho}}
\end{aligned}
$$

where

$$
\begin{array}{ll}
Q=q_{1}=q_{2} & \begin{array}{l}
\text { the mean flow rate }\left(\mathrm{m}^{3} / \mathrm{s}\right) \\
C_{d}
\end{array} \\
& \begin{array}{l}
\text { opening discharge coefficient, which } \\
\text { is independent of the internal } \\
\text { size/shape of the building } \\
\text { area of the opening }\left(\mathrm{m}^{2}\right)
\end{array} \\
\rho & \begin{array}{l}
\text { density of the air }\left(\mathrm{kg} / \mathrm{m}^{3}\right) \\
\text { mean static pressure difference }
\end{array} \\
\Delta P=P_{l}-P_{2} & \text { across the two opening }(\mathrm{Pa}), \\
& P=\frac{1}{2} C_{p} \rho U_{\text {ref }}^{2}
\end{array}
$$

$T_{e}, T_{i} \quad$ external, internal temperature (K)

$\Delta T=T_{i}-T_{e} \quad$ temperature difference

$h \quad$ distance between the two openings (m)

and the ' + ' or ' - ' sign indicates that the wind force complements or counteracts the buoyancy effect

\section{Full-scale experiment}

Field tests were carried out on the wind engineering site at the Silsoe Research Institute (SRI) under various weather conditions. Details on the full-scale experiments and set-ups are described in another paper [24]. Most data were collected on overcast days with indoor and outdoor temperature differences up to $8^{\circ} \mathrm{C}$, so that the buoyancy effect was not dominant. In order to ensure the quality of full-scale data, the mean ventilation flow rates of the cube were measured and evaluated by the following four methods simultaneously.

\subsection{Tracer gas decay method}

To determine qualitatively the ventilation flow rates in the cube, the tracer gas (carbon monoxide) was injected into the indoor space until the concentration had built up to $20 \mathrm{ppm}$. The CO decay history can be 
represented by $C(t)=C(0) e^{-I t}$ and it was logged at a sampling rate of $1 \mathrm{~Hz}$. The total air change rate was obtained from the slope of the decay curve's natural log-plot, $I$. Five portable mixing fans were placed within indoor space to achieve adequate air mixing.

\subsection{Mean static pressure and temperature difference measurements}

The pressure differences across the cube openings were recorded using a static pressure probe situated at each opening, and the indoor and outdoor temperature differences were recorded by temperature probes located at opening levels. Equation 5 (in Section 3.2) was applied to calculate the mean flow rates. Figure 5 shows the equipment arrangement at the high level opening.

\subsection{Surface pressure measurement around the opening}

As pictured in Figure 5, each surface pressure tap was mounted $0.5 \mathrm{~m}$ from the centre of the opening. The overall pressure differences were estimated by averaging the pressure difference from the two tapping points. Equation 5 is also employed to calculate the mean ventilation rate.

\subsection{Flow speed measurement at the centre of opening}

An ultrasonic anemometer (Gill Instrument Research R3 [25]) has been placed at each opening, and used to measure the instantaneous air velocity (see Figure 5). The mean ventilation rate was estimated using the mean speed of the inflow or outflow through the opening multiplied by the opening area $A$.

\section{Results}

The CFD results have been compared with the fullscale data collected on the Silsoe $6 \mathrm{~m}$ cube.

\subsection{Pressure coefficient on ventilated cube}

In order to identify the opening effects on the pressure distribution, the full-scale data on the sealed cube from the CWE2000 competition [10] (quoted as SRI Full-scale in Figure 6) were also plotted together with the CFD predictions of the cube with openings. The CFD predictions are named as 'CFX5 K-E' and
'CFX5 RNG', which represent the results simulated by the standard $k-\varepsilon$ model and RNG $k-\varepsilon$ model respectively.

It can be seen in Figure 6 that at $0^{\circ}$ wind direction CFX5 K-E and CFX5 RNG models produced similar pressure distributions on the windward wall. Significant differences occurred on the roof especially near the leading edge, and some discrepancies were shown around the higher opening. This is expected because flow separation from an edge of a bluff body creates a detached shear layer whose character depends strongly on the separation location. Wakes change accordingly in their overall form and general nature [26].

On the windward wall, the lower level opening had effects on the surface pressure distribution locally around the opening. On the leeward wall, the RNG model predicted more negative pressure above the opening and almost the same pressure just below the opening as the $k-\varepsilon$ model. More differences can be seen close to the ground, the RNG model simulated a lower value of negative pressure field than $k-\varepsilon$. Around each opening, the maximum value of 0.2 and minimum of 0.01 were the pressure coefficient difference between these two turbulence model results.

Regarding the average CPU time for simulation on a $1 \mathrm{GHz}$ Pentium III PC with 1 GB RAM, the RNG $k-\varepsilon$ model needed 1-day CPU time more than the standard $k-\varepsilon$ model, which used 8-hour of CPU time. The resulting flow field parameter differences between the two turbulence models were below $7 \%$ for the mean speed, and a maximum value of 0.2 for the pressure coefficients on the leeward wall. This accuracy level is acceptable in full-scale and wind tunnel experiments [6].

Hence, a compromise of numerical accuracy and computational time led to the choice of the standard $k$ - $\varepsilon$ model for the follow-up parametric studies of wind induced ventilation under various wind directions. 


\subsection{Mean ventilation rates comparison}

\subsubsection{Full-scale data}

The measured ventilation rates were nondimensionalised by the opening area $A$ and mean reference wind speed $U_{\text {ref. }}$. The well-established tracer gas decay method (in Section 4.1) is regarded as the most accurate method and is treated as the standard for comparison. The overall ventilation rate measured by the tracer decay method is $0.63 \pm 0.05$ for wind directions between $0^{\circ}$ and $30^{\circ}$, i.e. a standard deviation of $8.1 \%$ as shown in Table 3 .

Considering the pressure difference caused by wind effect alone (in Section 4.2) will result in an underprediction of $11 \%$. Better estimations with both the wind and thermal effects lead to values $2 \%$ closer to the effective ventilation rates obtained by method 1 (in Section 4.1).

In method 3 (Section 4.3), the surface pressures recorded by tapping points, provide the estimation of average pressure drop across the cube. This estimation has a relatively low difference (3\%) compared with the direct pressure measurement at the openings in method 2 (9\%).

Method 4 (measurement of flow speed at the centre of the low level opening) over-predicts the flow rate by $4 \%$ in average. Due to the turbulent external flow associated with the horseshoe vortex upstream of the building's front face and the crossflow over the lower opening, the single centre-point record could underpredict the mean inflow rate by $19 \%$ or over-predict by up to $11 \%$. In contrast, the mean outflow speed captured at the high level opening under-predicts the outgoing flow rate by $52 \%$ on average. This is probably caused by the unsteadiness of the velocity field in the wake of the building. The complicated flow profile through the opening and the velocity fluctuation feature cannot be represented by the single point measurement at the centre of the high level opening.

Comparatively speaking, the ventilation flow rates predicted by method 3 showed the closest agreement with method 1 mostly within 10\% 15\% agreement.

\subsubsection{Value of discharge coefficient}

It has been noticed that under certain wind directions high values of the opening discharge coefficients $\left(C_{d}\right)$ were required to give good agreement between the envelope flow model and measurement.

For a truly sharp-edged circular orifice in an infinite plane wall with still-air condition $0.6<C_{d}<0.65$ [27]. The possible reasons for using high $C_{d}$ in the present studies are:

(i) Using experimental method $1, Q$ is measured with tracer gas and will therefore include any effects of turbulence on the removal of tracer gas from the space.

(ii) The actual opening has a depth of $0.045 \mathrm{~m}$ with an aspect ratio of 2.3. Experiments conducted on a circular opening [28] have shown that a sharp-edged opening (zero depth as in CFD simulation), has a $C_{d}$ value of 0.6 . As the aspect ratio of the opening depth increases above zero, the $C_{d}$ value rises sharply. This value varied from $0.6 \sim 0.9$, peaking around a depth of 3 and staying high up to a depth of 7 .

(iii) The opening is not circular.

(iv) The $C_{d}$ value is defined on the basis of an external pressure and flow direction normal to the opening.

For wind directions within a $0^{\circ} \sim 30^{\circ}$ range, the $C_{d}$ value of 0.77 would give good agreement between theory and measurement. For the wind directions around $45^{\circ}$ cases, the upwind fetch conditions were affected by nearby buildings; method 1 recorded the total flow rate through the cube with a standard deviation of $21 \%$. A value of $C_{d}$ as 0.75 was chosen to take account of the effects of the large incident wind angle and the associated turbulent field around side walls and openings. This was done in order that the simulations agree with tracer gas experiments (method 1). For wind directions around $180^{\circ}$ cases, the relatively rougher upstream fetch causes the reduction of the wind speed and with cross flow presented at the high inlet opening location, the choice of $C_{d}$ as 0.6 gave reasonable agreement. Around the $90^{\circ}$ cases turbulent mechanisms were dominant, the value of 0.6 was chosen to give an 
over-prediction of $2 \%$ by method 3 compared to method 1.

\subsubsection{Comparison of full-scale data and CFD simulations}

In total $47 \mathrm{CFD}$ simulations were performed under various wind directions in line with the full-scale experimental data. For example, $10^{\circ}$ tests included 16 cases in which the wind direction varied from $9^{\circ}$ to $13^{\circ}$. Addtionally, the wind speed was varied between $2.97 \mathrm{~m} / \mathrm{s}$ and $5.61 \mathrm{~m} / \mathrm{s}$. The simulations are divided into 5 groups and listed in Table 4.

The ventilation rate was evaluated as in Section 4.3. Secondly, the mean ventilation rates were obtained by experimental method 3 .

Figure 7 shows the CFD predictions compared with experimental results around $10^{\circ}$ wind directions. Without considering the minor temperature difference effects, CFD results under-predicted the total effective flow rates through the building up to $12 \%$. The best fitting trend lines for all data in Figure 7 show that the ventilation rates increase with the increasing wind speed as expected. Without the scattered data usually found in experiments, it can be stated that fewer CFD modelling data are needed to extract the trend under specific weather conditions.

It is apparent in Figure 8 that CFD assessment of the mean ventilation rate for those wind directions that are around $90^{\circ}$ shows about $71 \%$ under-prediction of the experimental measurements by both method 1 and method 3. In this case, the ventilation may have been mainly caused by turbulent fluctuations in the wind, which are not predicted by the time-averaged, steadystate RANS simulations. Moreover, the standard $k-\varepsilon$ model is not able to capture the dominant mechanisms around the cube side walls, e.g. the unsteady separation and reattachment of flow.

\section{Discussion}

The ventilation associated with turbulent velocity fluctuations is not accounted for in the simpler forms of envelope model. Improved results for turbulence dominated flow prediction are expected through: (i) including turbulence effects by using unsteady envelope flow models [27, 29], which is relatively simple with quick solutions. However extensive knowledge of boundary conditions is needed; or

(ii) applying more sophisticated turbulence models, (e.g. Detached or Large Eddy Simulation, transient RANS [30]), which can predict more realistic turbulence, but demand considerable computational power and time; or

(iii) incorporating the automated simulaton facilities within CFD packages. This would involve placing the buildings under investigation on a turntable within the numerical domains and then automatically rotating the turntable according to the wind incident angles, to obtain the quasi-steady approximations using $80^{\circ}, 85^{\circ}, 95^{\circ}$ and $100^{\circ}$ flow fields. This is then simulated by RANS models combined with a weighting factor to calculate the ventilation rate for $90^{\circ}$ case [31]. This has been validated for wind engineering applications[31], but not ventilation studies.

The methods mentioned above would need further investigation using the experimental data for validation. Parallel wind tunnel experiments using scale models should be conducted in order to fill the gaps in full-scale data, and also to investigate the difference for ventilation studies between wind tunnel tests and field tests, e.g. Reynolds number or other scaling factor effects.

\section{Conclusions}

CFD has been applied to predict the natural ventilation rates in a full-scale cubic building with two realistic small size openings. When wind directions are near normal to the ventilation openings, i.e. $0^{\circ} \sim 30^{\circ}$, utilising the external surface pressures predicted by a RANS model in a simple envelope model proved capable of predicting the total ventilation rate to within $\pm 12 \%$ of measured values. The RANS model provides an understanding of the mean flow characteristics that could be used as guidance in design optimization.

When fluctuating pressures were large compared to mean values (at around $90^{\circ}$ ) RANS models were 
incapable of accurately predicting ventilation rate. Further work is required to collect more field data and to assess other CFD models (e.g. LES) at large wind incident angles.

\section{Acknowledgement}

This work has been funded by University of Nottingham and Silsoe Research Institute in the UK.

\section{Nomenclature}

\begin{tabular}{|c|c|c|}
\hline Symbol & Definition & Units \\
\hline$A$ & Area of opening & $\mathrm{m}^{2}$ \\
\hline$C_{d}$ & Opening discharge coefficient & - \\
\hline$C_{p}$ & Pressure coefficient & - \\
\hline$d P$ & $\begin{array}{l}\text { Mean static pressure difference across the } \\
\text { openings }\end{array}$ & $\mathrm{Pa}$ \\
\hline$d T$ & Indoor \& outdoor temperature difference & $\mathrm{K}$ \\
\hline$g$ & Gravitational acceleration & $\mathrm{m} / \mathrm{s}^{2}$ \\
\hline$h$ & Relative height of openings & $m$ \\
\hline$k$ & Turbulent kinetic energy & $\mathrm{m}^{2} / \mathrm{s}^{2}$ \\
\hline$Q$ & Mean flow rate & $\mathrm{m}^{3} / \mathrm{s}$ \\
\hline$T_{o}$ & Outdoor temperature & $\mathrm{K}$ \\
\hline$u, v, w$ & $\begin{array}{l}\text { Wind streamwise, spanwise, vertical } \\
\text { velocity components }\end{array}$ & $\mathrm{m} / \mathrm{s}$ \\
\hline$U, V, W$ & $\begin{array}{l}\text { Mean wind velocity component in } \mathrm{x}, \mathrm{y}, \mathrm{z} \\
\text { direction respectively }\end{array}$ & $\mathrm{m} / \mathrm{s}$ \\
\hline$U_{r e f}$ & Wind speed at reference height & $\mathrm{m} / \mathrm{s}$ \\
\hline$u_{*}$ & Friction velocity & $\mathrm{m} / \mathrm{s}$ \\
\hline$z$ & Height above the ground & $\mathrm{m}$ \\
\hline$z_{0}$ & Aerodynamic roughness height & $\mathrm{m}$ \\
\hline$z_{\text {ref }}$ & Wind velocity reference height & $\mathrm{m}$ \\
\hline$\rho$ & Density of air & $\mathrm{kg} / \mathrm{m}^{3}$ \\
\hline $\boldsymbol{K}$ & Von Karman's constant $\kappa=0.40$ & - \\
\hline $\mathcal{E}$ & Turbulence dissipation rate & $\mathrm{m}^{2} / \mathrm{s}^{3}$ \\
\hline
\end{tabular}

\section{References}

[1] Cook, M.J., Y. Ji, and G.R. Hunt, $C F D$ modelling of natural ventilation: Combined wind and buoyancy forces. International Journal of Ventilation, 2003. 1(3): p. 169179.

[2] Chen, Q., Using computational tools to factor wind into architectural environment design. Energy and Buildings, 2004(In press).
[3] Jiang, Y., D. Alexander, H. Jenkins, R. Arthur, and Q. Chen, Natural ventilation in buildings: Measurement in a wind tunnel and numerical simulation with large-eddy simulation. Journal of Wind Engineering and Industrial Aerodynamics, 2003. 91(3): p. 331-353.

[4] Nishizawa, S., T. Sawachi, K. Narita, H. Seto, and Y. Ishikawa, A wind tunnel fullscale building model comparison between experimental and cfd results based on the standard k-e turbulence representation. International Journal of Ventilation, 2003. 2(4): p. 419-429.

[5] Straw, M.P., Computation and measurement of wind induced ventilation, phd thesis, $\mathrm{PhD}$ thesis, in School of Civil Engineering. 2000, University of Nottingham, UK http://www.nottingham.ac.uk/ evzngw/down load.htm: Nottingham.

[6] Hoxey, R.P., P.J. Richards, and J.L. Short, $A$ $6 m$ cube in an atmospheric boundary layer flow part i. Full-scale and wind-tunnel results. Wind and Structures, 2002. 5(2-4): p. 177-192.

[7] Tsuchiya, M., S. Murakami, A. Mochida, K. Kondo, and Y. Ishida, Development of a new $k$-e model for flow and pressure fields around bluff body. Journal of Wind Engineering and Industrial Aerodynamics, 1997. 67 \& 68: p. 169-182.

[8] Hoxey, R.P., A.P. Robertson, B. Basara, and B.A. Younis, Geometric parameters that affect wind loads on low-rise buildings: Fullscale and cfd experiments. Journal of Wind Engineering and Industrial Aerodynamics, 1993. 50: p. 243-252.

[9] Murakami, S., A. Mochida, Y. Hayashi, and S. Sakamoto, Numerical study on velocitypressure field and wind forces for bluff bodies by k-e, asm and les. Journal of Wind Engineering and Industrial Aerodynamics, 1992. 41-44: p. 2841-2852.

[10] Richards, P.J., A.D. Quinn, and S. Parker, $A$ $6 m$ cube in an atmospheric boundary layer flow part 2. Computational solutions. Wind and Structures, 2002. 5(2-4): p. 177-192.

[11] Wright, N.G. and G.J. Easom, Non-linear $k-e$ model results for flow over a building at fullscale. Applied Mathematical Modelling, 2003. 27: p. 1013-1033. 
[12] Carey, P.S. and D.W. Etheridge, Direct wind tunnel modelling of natural ventilation for design purposes. Building Serv. Eng. Res. Technol., 1999. 20(3): p. 131-142.

[13] AEATechnology, CFX5 user manual, http://wwwwaterloo.Ansys.Com/product/CFX5/index.Ht ml. 2001.

[14] Raw, M. Robustness of coupled algebraic multigrid for the navier-stokes equations. in 34th Aerospace and sciences meeting \& exhibit. 1996. Reno.

[15] Cheng, Y., F.S. Lien, E. Yee, and R. Sinclair, A comparison of large eddy simulations with a standard k-e reynolds-averaged navierstokes model for the prediction of a fully developed turbulent flow over a matrix of cubes. Journal of Wind Engineering and Industrial Aerodynamics, 2003. 91: p. 13011328.

[16] Yang, T., N.G. Wright, D.W. Etheridge, and A.D. Quinn. Natural ventilation in a 6 m cube - fullscale \& cfd investigation. in 11th International Conference on Wind Engineering (ICWE2003), pp.1127-1134. 2003. Lubbock, USA.

[17] Yang, T., CFD and field testing of a naturally ventilated full-scale building, phd thesis, PhD thesis, in School of Civil Engineering. 2004, University of Nottingham, UK http://etheses.nottingham.ac.uk/91.

[18] AIAA. Guide for the verification and validation of computational fluid dynamics simulations (g-077-1998). in American Institute of Aeronautics and Astronautics. 1998.

http://www.aiaa.org/store/storeproductdetail. cfm?ID=558.

[19] ERCOFTAC, European research community on flow, turbulence and combustion "best practice guidelines for industrial computational fluid dynamics" http://imhefwww.Epfl.Ch/lmflercoftac/sigs/bp g.Html. 2000.

[20] Versteeg, H.K. and W. Malalasekera, Introduction to computational fluid dynamics: The finite volume method. 1995 , Harlow: Longman Scientific \& Technical.

[21] Easom, G., Improved turbulence models for computational fluid dynamics, $\mathrm{PhD}$ thesis, in
School of Civil Engineering. 2000, University of Nottingham, UK

http://www.nottingham.ac.uk/ evzngw/down load.htm: Nottingham.

[22] Richards, P.J. and R.P. Hoxey, Appropriate boundary conditions for computational wind engineering models using the k-epsilon turbulence model. Journal of Wind Engineering and Industrial Aerodynamics, 1993. 46\&47: p. 145-153.

[23] Etheridge, D.W. Theoretical and physical modelling of unsteady wind effects on timeaveraged natural ventilation. in 5 th $U K$ Conference on Wind Engineering (WES2002). 2002b. Nottingham.

[24] Yang, T., N.G. Wright, D.W. Etheridge, and A.D. Quinn, Field testing of a naturally ventilated full-scale building. 2005(In preparation).

[25] GillInstrumentsLtd, Ultrasonic research anemometer manual, http://www.Gill.Co.Uk/products/anemometer/ anemometer.Htm. 2000.

[26] Sharma, R.N. and P.J. Richards, The influence of reynolds stresses on roof pressure fluctuations. Journal of Wind Engineering and Industrial Aerodynamics, 1999. 83: p. 147-157.

[27] Etheridge, D.W. and M. Standberg, Building ventilation: Theory \& measurement. 1996, Chichester: John Wiley \& Sons.

[28] Shea, A. and A. Robertson. Discharge coefficients vary with depth of opening. in Silsoe Research Institute Seminar. 2004. Bedford, UK, 23 Jan 2004.

[29] Etheridge, D.W., Unsteady flow effects due to fluctuating wind pressures in natural ventilation design--mean flow rates. Building and Environment, 2000a. 35(2): p. 111-133.

[30] Jiang, Y. and Q. Chen, Effect of fluctuating wind direction on cross natural ventilation in buildings from large eddy simulation.

Building and Environment, 2002. 37: p. 379386.

[31] Richards, P.J. Quasi-steady theory developed with experimental verificaiton. in Silsoe Research Institute Seminar. 2004. Bedford, UK, 23 Jan 2004. 


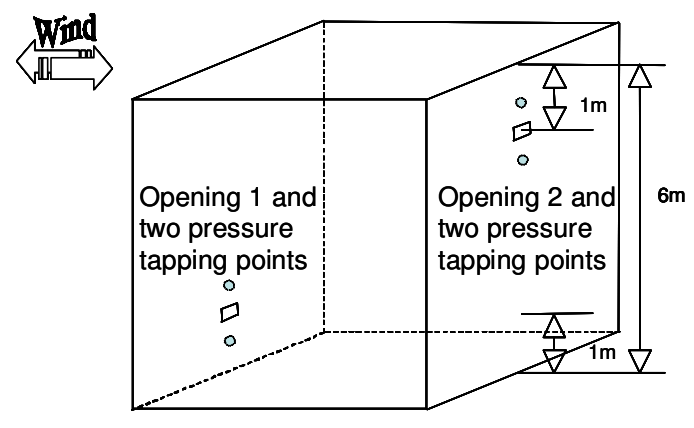

Figure 1. Schematic diagram of the $6 m$ cube with two rectangular openings

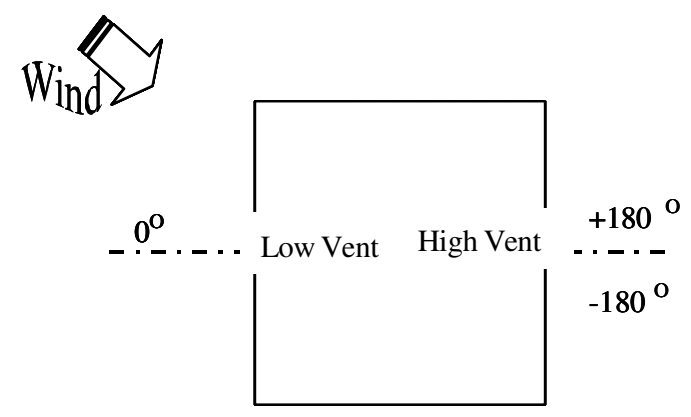

Figure 2. Wind incident angles (cube top plan view)

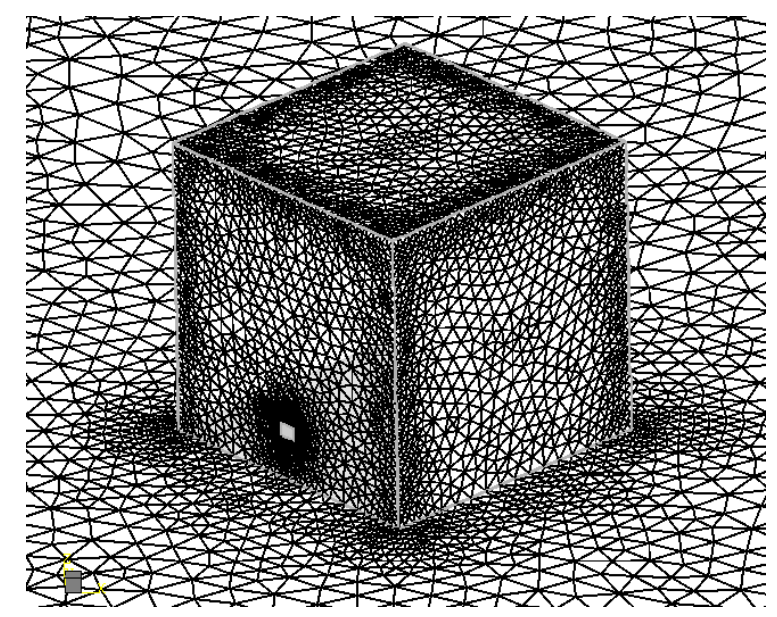

Figure 3. Illustration of unstructured mesh settings for the fine mesh (grid resolution 40) 
Final draft submitted to the International Journal of Ventilation_2006

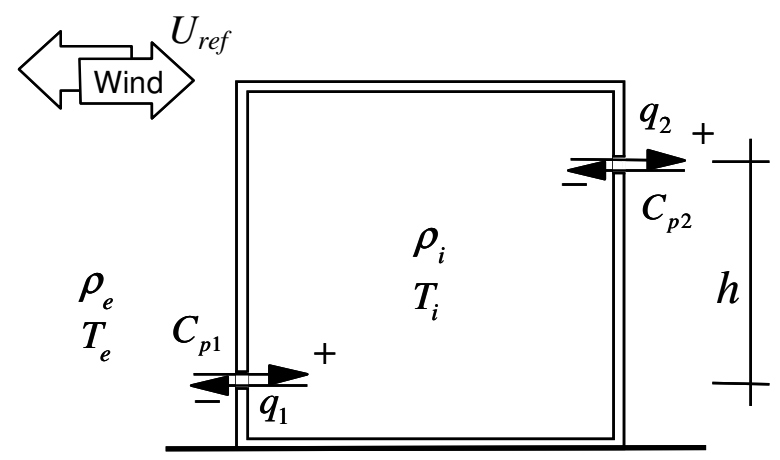

Figure 4. Flow parameters in ventilation studies

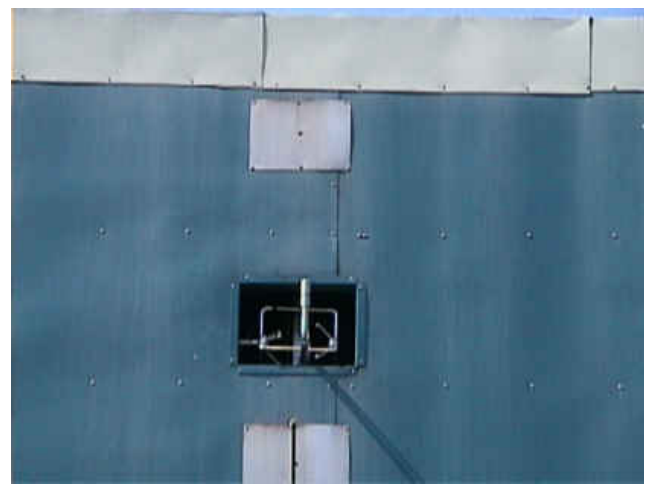

Figure 5. An ultrasonic anemometer, a static pressure probe placed at the high level opening and two pressure taps near the opening

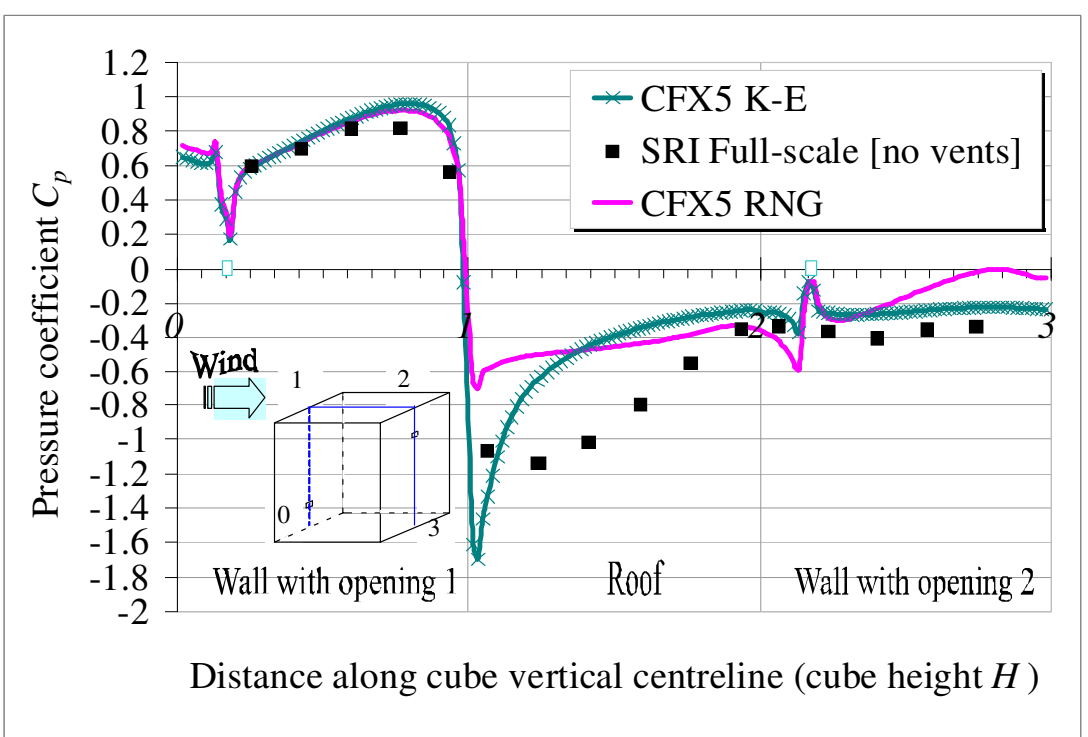

Figure 6. Mean pressure coefficients along cube vertical centreline ( $0^{\circ}$ wind direction) 


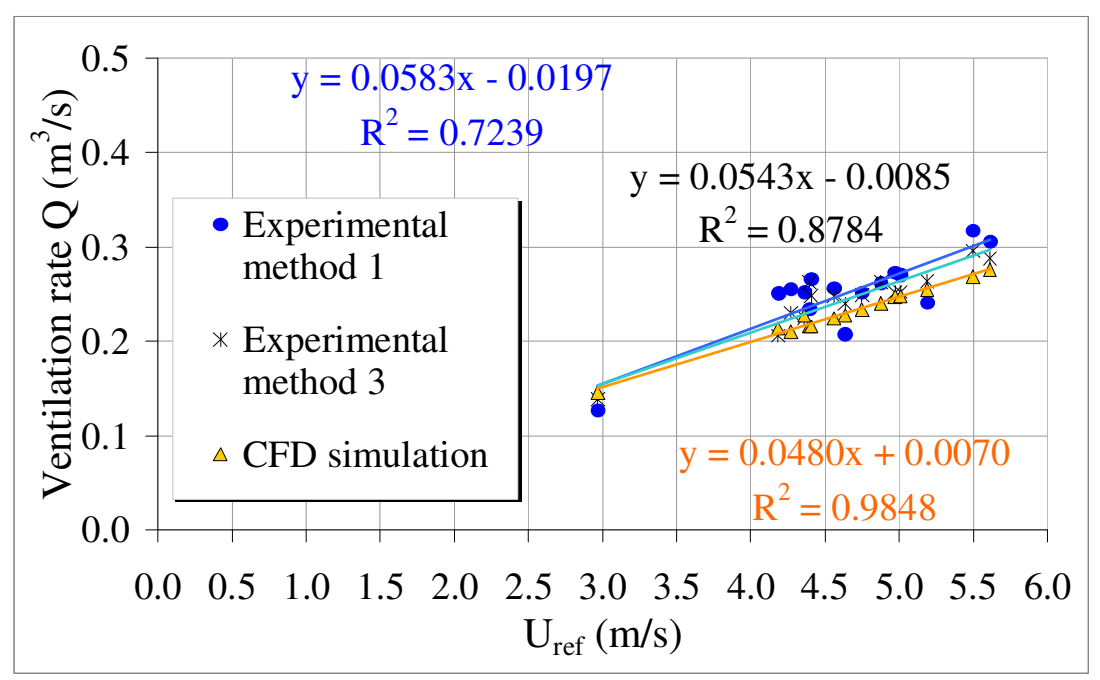

Figure 7. Measured and predicted ventilation rates around $10^{\circ}$

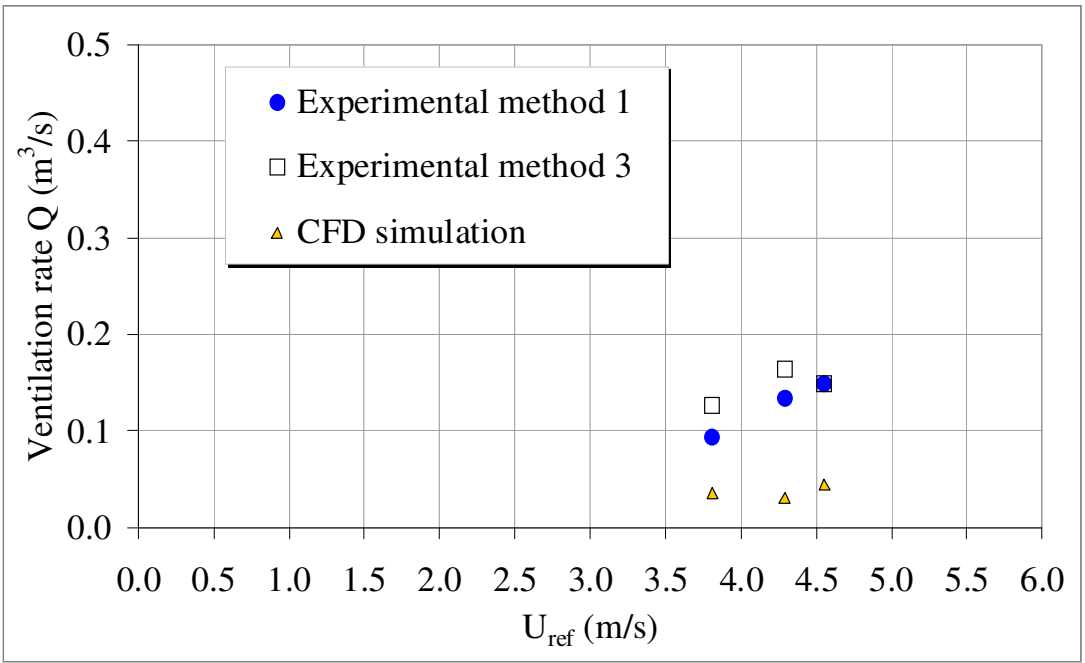

Figure 8. Measured and predicted ventilation rates around $90^{\circ}$ 
Final draft submitted to the International Journal of Ventilation_2006

Table 1: Boundary conditions in CFX5.5.1

\begin{tabular}{|c|c|}
\hline Boundary & Settings \\
\hline Inlet & Log-law velocity profile with specified $k \& \varepsilon$ (Eqn.1 - Eqn.4) \\
\hline Outlet & $\begin{array}{l}\text { relative static pressure is zero; } \\
\text { normal gradient of other variables is zero, i.e. } \partial / \partial x=0\end{array}$ \\
\hline Ground & no-slip rough wall (roughness height $=0.01 \mathrm{~m}$ ) \\
\hline Cube surfaces & no-slip rough wall (roughness height $=0.005 \mathrm{~m}$ ) \\
\hline Upper domain & symmetry (vertical velocity component $w=0 \& \partial / \partial z=0)$ \\
\hline Side domains & symmetry (spanwise velocity component $v=0 \& \partial / \partial y=0)$ \\
\hline
\end{tabular}

Table 2. Mesh types

\begin{tabular}{ccccr}
\hline $\begin{array}{c}\text { Mesh } \\
\text { Name }\end{array}$ & $\begin{array}{c}\text { Mesh } \\
\text { length scale }(\mathrm{m})\end{array}$ & $\begin{array}{c}\text { Resolution } \\
\text { on surface }\end{array}$ & $\begin{array}{c}\text { Resolution } \\
\text { at opening }\end{array}$ & Elements \\
\hline Grid 15 & 0.40 & 15 & 5.00 & 930,000 \\
Grid 20 & 0.30 & 20 & 6.25 & $1,170,000$ \\
Grid 40 & 0.15 & 40 & 12.50 & $1,450,000$ \\
\hline
\end{tabular}

Table 3. Cube ventilation rates for $0^{\circ} \sim 30^{\circ}$ cases

\begin{tabular}{|c|c|c|c|c|}
\hline \multirow{2}{*}{\multicolumn{2}{|c|}{82 test cases }} & \multicolumn{2}{|c|}{$Q /\left(U_{r e f} A\right)$} & \multirow{3}{*}{$\begin{array}{c}\text { Mean } \\
\text { Difference } \\
(\%) \\
-\end{array}$} \\
\hline & & \multirow{2}{*}{$\begin{array}{c}\text { mean } \pm \text { SD }^{*} \\
(-)\end{array}$} & \multirow{2}{*}{$\begin{array}{c}\text { SD/mean } \\
(\%)\end{array}$} & \\
\hline Method 1 & $\{C O d e c a y\}$ & & & \\
\hline \multirow[t]{2}{*}{ Method 2} & $\{d P\}$ & $0.56 \pm 0.04$ & 7.5 & -11 \\
\hline & $\{d P+d T\}$ & $0.57 \pm 0.04$ & 7.8 & -9 \\
\hline Method 3 & $\left\{d P_{\text {taps }}+d T\right\}$ & $0.61 \pm 0.04$ & 5.9 & -3 \\
\hline \multirow[t]{2}{*}{ Method 4} & Sonic(in) & $0.65 \pm 0.04$ & 6.6 & 4 \\
\hline & Sonic(out) & $0.30 \pm 0.02$ & 7.4 & -52 \\
\hline
\end{tabular}

\# Mean difference $=\left(\left(Q-Q_{\text {method } 1}\right) / Q_{\text {method } 1}\right) \times 100 \%$

$+\mathrm{C}_{\mathrm{d}}=0.77$ in Method 2 and 3

Table 4: Experimental values selected for CFD simulations

\begin{tabular}{|c|c|c|c|c|c|}
\hline \multirow[t]{2}{*}{ Test } & \multicolumn{3}{|c|}{ Wind direction } & \multirow[b]{2}{*}{$90^{\circ}$} & \multirow[b]{2}{*}{$180^{\circ}$} \\
\hline & $0^{\circ}$ & $10^{\circ}$ & $30^{\circ}$ & & \\
\hline No. of cases & 9 & 16 & 6 & 3 & 13 \\
\hline$C_{d}(-)$ & 0.77 & 0.77 & 0.77 & 0.6 & 0.6 \\
\hline$U_{r e f}(\mathrm{~m} / \mathrm{s})$ & $3.51 \sim 5.12$ & $2.97 \sim 5.61$ & $2.70 \sim 5.58$ & $3.81 \sim 4.55$ & $2.64 \sim 4.51$ \\
\hline$Q\left(\mathrm{~m} / \mathrm{s}^{3}\right)$ & $0.18 \sim 0.30$ & $0.13 \sim 0.32$ & $0.19 \sim 0.27$ & $0.09 \sim 0.15$ & $0.11 \sim 0.23$ \\
\hline
\end{tabular}

